\title{
Research on Data Processing Core Course Group of Internet of Things
}

\author{
Yangqing Zhu \\ Electronic and Information Engineering School \\ Foshan University \\ Foshan City, China \\ zhuyangqing_830516@163.com
}

\begin{abstract}
To abandon the ideas of traditional single curriculum construction, take research and application of Internet of Things as the main direction of research and construction of core curriculum group, take data processing direction of Internet of Things as an example, carried out research on the construction of the core curriculum group. Formed the integration construction ideas of application system project, technology and curriculum, and put forward the path of data processing core course group of resource construction and teaching, which provided a reference scheme for training university students' application ability and innovation ability.
\end{abstract}

\section{Keywords—Data Processing of Internet of Things; Core Curriculum Group; Project Driven; Curriculum Synergy.}

\section{INTRODUCTION}

The Internet of Things is the third information revolution following the computer and the Internet, its application involves the integration of physical and virtual world, to solve the problems of this field, need to have comprehensive knowledge and ability, therefore, need the corresponding professional personnel training. The Internet of things is a cross subject, involving computer, communication technology, electronic technology, measurement and control technology and other professional knowledge, as well as management, software development and many other aspects of knowledge [1]. In the process of construction and improvement of specialized courses, the single discipline curriculum system cannot be applied to the application of Internet of things, and the interdisciplinary teaching model can meet the requirements of professional curriculum construction. Similarly, to refine the course construction, the closed course construction has been unable to meet the requirements of cross disciplinary knowledge system, in urgent need of related courses integration and the overall planning, to form curriculum group construction. [2]

The research and application direction of Internet of Things engineering can be divided into detection and control, data processing, security Internet of Things, etc. For the cultivation of high quality talents with innovation and practice ability, the course construction of Internet of Things professional should carry out the core curriculum group construction according to research and application direction of Internet of Things, to improve the efficiency and quality of teaching and personnel training. [3]

In this paper, took the data processing research and application direction of Internet of Things as an example, studied the connotation of the core course group of Internet of Things data processing, took project driven and collaborative curriculum as the guiding ideology, put forward the data processing core course group construction ideas of Internet of Things and measures of teaching reform, to provide a reference path for training engineering talents with independent learning, innovation, collaboration and comprehensive application ability.

\section{The GUIDING IDEOLOGY OF CORE CURRICULUM GROUP CONSTRUCTION}

The target of core course group construction should include a solid foundation of knowledge, problem-solving skills, teamwork and leadership ability, cognitive ability, professional ability of social impact assessment, global awareness ability and lifelong learning ability. [4]

In the construction of the core curriculum group system, should take full account of the characteristics of the industry talents demand and the new trends of innovation and entrepreneurship.

Insist on the teaching concept of continuous improvement. Continuous improvement is the basic idea of modern management, its main idea is the quality management activities and results through the process improvement implementation, emphasizes prevention, uninterrupted control, so that the management level and the quality of work organization rising. In the teaching quality management, introduce the idea of continuous improvement, emphasizing the gradual progress, avoiding eager for quick success and instant benefit. The law of teaching determines that improving the quality of teaching is a long-term process. Therefore, continuous improvement is an important principle to improve teaching quality. [5]. 


\section{Connotation of Core Courses Group of Data Processing of INTERnEt of Things}

The Internet of things has three levels, namely, the perception layer, the network layer and the application layer. According to the data flow, the Internet of things can be divided into four levels, namely, the perception layer (data acquisition layer), the transmission layer, the platform layer (data processing layer) and the application layer [6]. The research and application direction of Internet of things engineering can be divided into detection and control, Internet of things data processing, Internet of things security, etc. The Internet of Things data processing includes data acquisition, data quality control, data transmission, data storage, data calculation, data compression, data integration, data query and so on. The technologies involves many courses. On the basis of the four layer theory of Internet of things, this paper studied the core courses of data processing in Internet of things, and formed the core curriculum group structure of the Internet of things data processing as shown in figure 1 .

\begin{tabular}{|c|c|}
\hline The Layers of Internet of Things & Course Name \\
\hline Data Application Layer & $\begin{array}{c}\text { Internet of Things Application Systems: Air Environment Detection } \\
\text { System, Water Environment Monitoring System, Smart Agricultural } \\
\text { Greenhouse, Smart Transportation, Smart Medical Care, Smart } \\
\text { Logistics, Smart Home, etc. }\end{array}$ \\
\hline Data Processing Layer & $\begin{array}{c}\text { Object Oriented Programming, Database System Principle, Data } \\
\text { Technology, Mobile Application Development, etc. }\end{array}$ \\
\hline Data Transmission Layer & $\begin{array}{c}\text { Computer Network, Communication Technology of Internet of Things, } \\
\text { etc. }\end{array}$ \\
\hline Data Acquisition Layer & $\begin{array}{r}\text { Sensor Principle and Detection Technology, Wireless Sensor Network } \\
\text { and RFID Technology Principle, etc. }\end{array}$ \\
\hline
\end{tabular}

Figure 1. The Core Curriculum Group Structure of the Internet of Things Data Processing

\section{CONSTRUCTION IDEAS}

The construction of the core course group of data processing of Internet of things is based on the idea of project driven and curriculum synergy. In the beginning stage of curriculum group construction, the teachers team carefully analyze the data processing of Internet of Things involves some typical application system projects, such as air environment detection system, water environment monitoring system, smart agricultural greenhouses, smart transportation, smart medical care, smart logistics, smart home and so on. Analyzed data acquisition, data transmission, data storage, data processing, data display technologies of the projects, and combine these technologies with the corresponding courses, formed an integration thinking of the application sy stem project, the related technology and the related courses. [7]

In the curriculum organization, the importance and difficulty of each course should be highlighted, and each course in the group should be constructed with different levels and based on different main lines. To the specialized basic courses, should attach importance to its basic theory construction. To the professional courses of applied and comprehensive design courses, should attach importance to its practice, and to train students' application ability as the main line, and reflect the new requirements of more precision and wider thinking. Detailed arrangements, highlighting the main content, hierarchical construction, improve the overall construction effect of the curriculum within the group. In the process of building a single curriculum, not only construct the basic concepts, basic principles and other curriculum resources of the related technology, but also take the project development as the main line, to construct the curriculum resources related with the project development. [8]

\section{TEACHING REFORM MEASURES}

\section{A. Strengthen the Discussion of Curriculum Group Teachers}

Strengthen teaching research and discussion of course group teachers, compressed the duplicate content through the relationship of time and content of the adjacent courses. Highlight application, basic theory knowledge should take the essential and sufficient as principle, abandon the meticulous, professional and old content, to determine the course content, their association and its proportion in the course group. Then, determine the number of teaching hours according to the proportion, and new textbooks are written or chosen according to the content. Every teacher should be familiar with the contents of himself teaching course and related courses, students have learnt the curriculum knowledge, the depth of knowledge and how to teach this course, so that students can better understand the new knowledge in the following lessons. 


\section{B. Pay Attention to New Technologies of Internet of Things}

Correctly handle the relatively stable and constant updating of the teaching content, and keep the content forward and forwardlooking. Pay attention to the current development situation of the Internet of Things discipline and related disciplines content, to enable students to understand the development of Internet of Things technology new achievements, new ideas, new problems and new trends, and take these new knowledge timely supplement to the teaching content.

\section{Teachers Teaching Cross Courses}

The teacher of the course group taught cross courses, familiar with all the contents of the course curriculum group, fully understand the real connotation of the teaching strategies of curriculum - technology - the actual project development, and truly reflected the teaching strategies into the teaching process.

\section{Select Excellent Teaching Books}

The curriculum group construction and selection of excellent teaching materials was promoting each other. On one hand, the main content of teaching directly reflected in teaching materials, how to integrate curriculum and how to reflect the latest scientific and technological achievements in the teaching process, need carry out optimal combination to the teaching books, on the other hand, curriculum group construction achievements must also be to reflect the construction of teaching materials. Therefore, it is vital importance to build a series of characteristic textbooks.

\section{E. Practice Teaching}

Practice teaching has always been an important teaching link of the Internet of things. Therefore, the construction of laboratory is one of the important contents of the construction of the curriculum group. It focuses on the construction of specialized experiments in the process of curriculum group construction, and optimizes the experimental resources. In the course group, each course has practical links, so the course group teachers are the main force of the laboratory construction.

For the current major problems of the experiment, such as relative to a single experiment content and relative to a single project, comprehensive experimental design was less and not difficult, no association between the experimental course, the arrangement of the content has been not considering the continuity problems of related courses. Therefore, starting to design practice of the whole courses from the point of view of system, establish the connotation of curriculum group Internet of Things data processing for capabilities and skills training. The specific experimental content was divided into two series and three levels. The two series were compulsory courses within the course and extracurricular selection series. The three levels were composed of three parts: curriculum experiment, special topic research experiment and independent innovation experiment. The first layer of the course experiment mainly included verify and simple experiment. The second layers of curriculum was design experiment. The third layer was characteristic courses of the curriculum group, but also the implementation level of production, learning and research, use existing resources and scientific research courses to set up relevant practice outside university.

\section{F. Laboratory Management}

The laboratory should be open to students in all aspects and all round the clock to make it an integrated, innovative and research-based practice teaching base for students. Through the open experiment project and the open laboratory, to improve the students' practical ability and operation ability. Through the construction of practice bases, to hire outside relevant experts and technical personnel to carry out activities courses, strengthen the link of teaching and social practice, understand social needs, to provide a good environment for cultivating students' practical ability, improve the students' professional practice ability.

\section{SUMMARY}

The Internet of things is a closely related discipline with practice, data processing is an important research and application direction of the Internet of things. Should be closely combined with the enterprise practice, starting from practical application system, set up teaching ideas through practical projects, technology and course, create a core curriculum group, reform the traditional teaching process, achieve the effective coordination of the courses, teaching materials and teachers, to cultivate talents for meeting the social needs of Internet of things data processing.

\section{ACKNOWLEDGMENT}

This research was financially supported by the open innovation fund of Foshan University laboratory.

\section{REFERENCES}

[1] Xu Huang, Yunlang Jiang, Yonggen Gu. Practice and Exploration of Multi-disciplinary Integration in the Construction of Internet of Things Engineering. Research in Higher Education of Engineering, 2016, 2: 86-90.

[2] Guizhu Liu, Jie Yang, Yaohua Hu, Xiupin Li, Shanjin Wang. The Core Curriculum Group Construction in the Major of Electronic Information. Journal of Electrical \& Electronic Education, 2016, 2: 36-38. 
[3] Hailong Wang, Shuqian Zhang, Weiguang Liu. Research and Exploration of Personnel Training in Internet of Things. Computer Education, 2015, 1: 12-16.

[4] Ping Yang, Changrong Chen. Exploration on the Construction of Information Literacy Curriculum Group. Journal of Chongqing University of Science and Technology (Social Sciences Edition), 2015, 11: 42-46.

[5] Qiufeng Wu, Hongxia Li, Yang Shen. Research on the Teaching Reform of Higher Engineering Specialty Based on the OBE. Education Exploration, 2016, 5: 97-100.

[6] Qibo Sun, Jie Liu, San Li, Chunxiao Fan, Juanjuan Sun. Internet of Things: Research Review of Concepts, Architectures and Key Technologies. Journal of Beijing University of Posts and Telecommunications, 2010, 3: 1-9.

[7] Jingyuan He. Technology and Application Research of Internet of things. Telecom World, 2016, 8: 41-42.

[8] Ge Jiao, Lang Li, Yi Zhou. Practical Teaching Design of Intelligent Control Projects Based on Internet of Things. Computer Ed ucation, 2016, 10: 34-36. 